\title{
ESTUDO DE IMPACTOS CAUSADOS POR LANÇAMENTO DE EFLUENTES NA CONCESSÃO DE OUTORGA ATRAVÉS DE MODELOS MATEMÁTICOS, COM APLICAÇÃO EM RIOS DO RIO GRANDE DO NORTE - BRASIL
}

\author{
Patrícia Freire Chagas ${ }^{1}$ \\ Raquel Jucá de Moraes Sales ${ }^{2}$ \\ Juliana Alencar Firmo de Araújo ${ }^{3}$
}

\begin{abstract}
RESUMO
Este estudo analisa os impactos causados em alguns rios do Estado do Rio Grande do Norte, localizado no Nordeste brasileiro, em processo de concessão de outorga de efluentes domésticos. Para tanto, foi desenvolvido um modelo matemático, com base no Princípio de Conservação de Massa, que permitisse a avaliação da vazão de diluição para cada lançamento. As simulações foram realizadas utilizando-se o programa computacional, em linguagem FORTRAN, desenvolvido para esta pesquisa. A partir dos resultados, observou-se que os rios do Rio Grande do Norte não têm capacidade de diluição em alguns períodos do ano, por possuírem baixa vazão. Ainda que alguns rios em análise possuam certa capacidade de diluição, em alguns trechos específicos, esses rios necessitam de análises para cada trecho, não permitindo, por sua vez, uma única análise de concessão de outorga. A prática de conceder a licença de uso com base em trechos pode trazer sérios ricos para a vida aquática no trecho em que foi concedida a outorga. Por este motivo, é necessário que seja feita uma avaliação criteriosa para a concessão de outorga de lançamento de efluentes nesta região.
\end{abstract}

PALAVRAS-CHAVE: Capacidade Receptora dos Rios. Outorga de Lançamentos. Poluição Hídrica.

\section{IMPACT STUDY FOR WASTEWATER RELEASE CAUSED IN GRANTING CONCESSION THROUGH MATHEMATICAL MODELS WITH APPLICATIONS IN RIVERS IN RIO GRANDE DO NORTE - BRAZIL}

\footnotetext{
ABSTRACT

This study analyzes the impacts caused in rivers of the State of Rio Grande do Norte, Northeast of Brazil, in the concession process of grants of domestic sewage. With this purpose, a mathematical model was developed with base in the Conservation of Mass Principle, which allowed that the dilution flow for each release could be evaluated. The simulations were accomplished by the aid of a Computational Program, in FORTRAN CODE, developed for this research. The results showed that

${ }^{1}$ Doutora em Engenharia Civil - Recursos Hídricos - Universidade Federal do Ceará. Campus do Pici, CEP-60445-760. Bloco 713. Fortaleza - Ceará. e-mail: pfchagas@yahoo.com.

${ }^{2}$ Doutora em Engenharia Civil - Recursos Hídricos - Universidade Federal do Ceará. Campus do Pici, CEP-60445-760. Bloco 713. Fortaleza - Ceará. e-mail: raqueljuca@gmail.com.

${ }_{3}^{3}$ Mestre e doutoranda em Engenharia Civil - Recursos Hídricos - Universidade Federal do Ceará. Campus do Pici, CEP-60445-760. Bloco 713. Fortaleza - Ceará. e-mail: judiaraujo@yahoo.com.br.
} 
rivers of Rio Grande do Norte do not have dilution capacity in long period of the year, caused by the low Although some rivers in question have certain dilution capacity in some specific sections, these rivers need analyzes for each section, not allowing, in turn, a single grant award analysis flow. In such way, the results showed that there is necessity to do a permanent analysis in order to make concession of grants of effluents release.

PALAVRAS-CHAVE: River Water Quality. Effluents Discharges. Water Pollution.

\title{
ESTUDIO DE IMPACTO DE LA LIBERACIÓN DE AGUAS RESIDUALES CAUSADO EN OTORGAMIENTO DE CONCESIÓN TRAVÉS DE MODELOS MATEMÁTICOS CON APLICACIONES EN RIOS EM RIO GRANDE DO NORTE - BRASIL
}

\begin{abstract}
RESUMEN
Este estudio analiza los impactos en algunos ríos del Estado de Rio Grande do Norte, que se encuentra en el noreste de Brasil, en el proceso de otorgamiento de concesiones de aguas residuales domésticas. Para ello, un modelo matemático se desarrolló basándose en el principio de conservación de la masa, lo que permite la evaluación del flujo de dilución para cada lanzamiento. Las simulaciones se realizaron utilizando el programa de ordenador en FORTRAN, desarrollado para esta investigación. De los resultados, se observó que los ríos de Río Grande del Norte no tienen capacidad de dilución en algunos períodos del año, ya que tienen poco caudal. Aunque algunos ríos en cuestión tienen cierta capacidad de dilución en algunas secciones específicas, estos ríos necesitan análisis para cada sección, no permitiendo, a su vez, un solo análisis de una concesión. La práctica de conceder la licencia en base a extractos puede traer rica grave para la vida acuática en el tramo en el que se concedió la subvención. Por esta razón, se debe hacer una cuidadosa evaluación para la concesión de la descarga de efluentes concedido en esta región.
\end{abstract}

PALABRAS CLAVE: . Calidad del Agua. Las Descargas Del Efluentes. La Contaminación Del Agua.

\section{INTRODUÇÃO}

Para disciplinar os usos dos corpos aquáticos, inclusive no lançamento de efluentes, surgiram leis específicas para os recursos hídricos. Embora já houvesse legislação ambiental que contemplasse esta área, as decisões tomadas, em relação a sua utilização, eram insuficientes para evitar a sua poluição e assegurar disponibilidade hídrica para os seus usuários, com padrões de qualidade para diferentes usos.

A outorga para lançamento de efluentes, conforme consta na Lei Federal ํ․ 9.433/97, permite que, após uma descarga em um curso de água, com carga máxima de poluentes, e sua diluição sob vazão mínima fixada como referência, tenha qualidade de água satisfatória no corpo receptor, conforme os objetivos de qualidade estabelecidos pela classe do uso (CRUZ, 2001). 
Ao se emitir uma outorga, o volume outorgado fica indisponível, total ou parcialmente, para outros usos no corpo hídrico em que é feita a captação ou diluição e nos corpos hídricos situados a jusante, considerada a capacidade de autodepuração (NAHON, 2006). O volume de água outorgado poderá variar em função da sazonalidade, da disponibilidade efetiva e da necessidade de uso da água.

Com base nos processos de difusão, para que fosse possível estudar a capacidade de autodepuração de rios sujeitos a lançamento de efluentes, foi desenvolvida uma metodologia, utilizando o modelo matemático concentrado, que permitisse a simulação de diferentes cenários de lançamento em rios. No estudo, foram analisados cenários de lançamento para vários rios do Estado do Rio Grande do Norte - RN. Com isto, espera-se contribuir para o fortalecimento da sistemática de outorga para lançamento de efluentes no RN.

\section{OUTORGAS PARA LANÇAMENTO DE EFLUENTES}

Tratando-se especificamente da outorga, existem diversos usos dos recursos hídricos nos quais os usuários estão sujeitos a requerer outorga do Poder Público, como derivação ou captação de uma parcela da água existente em um corpo d'água; extração de água de aquífero subterrâneo; lançamento de esgotos em corpos d'água e demais resíduos líquidos ou gasosos, tratados ou não, a fim de sua diluição, transporte ou disposição final; aproveitamento dos potenciais hidrelétricos; e outros usos que alterem o regime, a quantidade ou a qualidade da água.

As atividades e usos de uma bacia hidrográfica estão diretamente ligados à qualidade de água e, em função desta multiplicidade de atividades, é de grande valia conhecer antecipadamente a magnitudes dos danos que podem ocorrer no ambiente, em virtude do despejo de cargas poluidoras, tanto para que o homem possa usufruir futuramente desses recursos, como para a própria preservação ambiental (MACHADO et al., 2003).

A classe de uso prevista em lei está associada ao aceite de valores de qualidade da água estabelecidos na forma de padrões (Resolução do CONAMA № 357, de 17 de março de 2005). Os padrões, por sua vez, são os valores 
estabelecidos por lei, com base no respaldo científico, que garantem a segurança dos usos estabelecidos.

Já a outorga, por ser um instrumento que envolve direitos de uso, é um dos documentos exigidos no processo de licenciamento ambiental (Resolução CONAMA № 237/97). Portanto, os órgãos gestores de meio ambiente e de recursos hídricos deverão trabalhar de forma plenamente articulada, haja vista que a decisão a ser tomada é totalmente interdependente, ou seja: as eficiências de tratamento de efluentes definidas na licença de instalação ambiental e as correspondentes cargas poluidoras remanescentes, deverão estar em perfeita consonância com as vazões que poderão ser alocadas para a diluição desses poluentes, e vice-versa (SILVA e MONTEIRO, 2004).

\section{METODOLOGIA}

Como aporte metodológico, foi desenvolvido e aplicado um sistema de apoio à análise de outorga de lançamento de efluentes, em relação à matéria orgânica e aos coliformes fecais, para o fortalecimento da Política Estadual de Recursos Hídricos do Rio Grande do Norte. Este sistema é constituído pelo cálculo da vazão apropriada para a diluição de efluentes, de forma que esta vazão seja necessária para diluir o efluente, mantendo o corpo receptor em padrões de qualidade compatíveis com a sua classe de enquadramento.

Nas simulações, a Demanda Bioquímica de Oxigênio (DBO) e a presença de coliformes fecais foram utilizados como parâmetro de avaliação da capacidade de autodepuração do rio, sendo importantes indicadores de poluição hídrica. Neste contexto, tomou-se como referência a classificação dos rios segundo a resolução do CONAMA 357/05. Os limites das concentrações permitidas para cada classe de rio, estabelecidas segundo a resolução são apresentados na Tabela 1.

Tabela 1: Limites de concentração para alguns parâmetros.

\begin{tabular}{|c|l|l|l|l|l|l|}
\hline Classe & & \multicolumn{1}{|c|}{ Especial } & \multicolumn{1}{|c|}{$\mathbf{1}$} & \multicolumn{1}{|c|}{$\mathbf{2}$} & \multicolumn{1}{|c|}{$\mathbf{3}$} & $\mathbf{4}$ \\
\hline \multirow{2}{*}{ Coliformes } & Fecais & Ausentes & $<200$ & $<1000$ & $<4000$ & - \\
\cline { 2 - 7 } & Totais & Ausentes & $<1000$ & $<5000$ & $<20000$ & - \\
\hline DBO $_{5}$ (mg/L) & & Ausente & $<3$ & $<5$ & $<10$ & - \\
\hline
\end{tabular}

Fonte: Própria (2014). 
Sabendo que no processo de dispersão de efluentes em corpos hídricos se deve levar em conta os princípios básicos que governam o transporte de massa poluente, nesta pesquisa, aplicou-se o princípio da conservação das massas em um campo permanente de velocidade, de maneira que fosse possível avaliar o comportamento das concentrações de alguns parâmetros considerados representativos para tal estudo. Aplicando o referido princípio em um sistema hídrico qualquer, as equações do cálculo da vazão de diluição podem ser obtidas.

\section{Cálculo da vazão de diluição}

O lançamento de efluentes domésticos ou industriais acarreta agregação de poluentes no rio, o que exigirá do corpo hídrico certa quantidade de água (vazão de diluição) para diluir os poluentes, sendo diretamente proporcional à carga do mesmo. Essa vazão de diluição é exatamente a quantidade de água que será outorgada, ou seja, concedida para o usuário que deseja lançar poluentes em um corpo de água receptor.

A formulação para o Cálculo da Vazão de Diluição, Equação 1, é desenvolvida a partir do princípio da conservação das massas, aplicada em sistemas hídricos com escoamento permanente. Neste caso, admite-se que ocorre diluição instantânea, logo após o lançamento do efluente. É importante notar que não é considerado o efeito do decaimento para substâncias não conservativas.

$$
Q_{d}=Q_{w}\left(\frac{C_{w}-C_{p}}{C_{p}-C_{r i o}}\right)
$$

\section{Equação 1}

Onde $Q_{d}$ é a vazão de diluição; $Q_{w}$ é a vazão do efluente; $C_{w}$ é a concentração do efluente; ${ }^{C_{p}}$ é a concentração permitida para cada classe de rio; e $C_{\text {rio }}$ é a concentração do rio.

Para o caso de substâncias com decaimento, o cálculo da vazão de diluição é realizado admitindo-se que a substância sofre decaimento, Equação 2.

$$
Q_{d}=\frac{Q_{w} C_{w}}{C p} \exp \left(-k \frac{x}{U}\right)
$$

Equação 2

Onde $k$ é o coeficiente de decaimento da substância; $U$ é a velocidade do rio; $C p$ é a concentração permitida; $Q_{w}$ é a vazão do efluente; $C_{w}$ é a concentração do efluente. 
Para alcançar os objetivos do estudo, desenvolveu-se um programa computacional, em linguagem FORTRAN, capaz de simular a diluição do rio, para diferentes lançamentos de efluentes. O programa tem uma estrutura composta de 5 sub rotinas que dão suporte a todos os cálculos das principais variáveis de controle. Neste programa, considerou-se permanente o escoamento do rio, e a vazão de diluição foi calculada imediatamente após o lançamento.

\section{RESULTADOS E DISCUSSÕES}

A partir da fundamentação matemática, seguindo o princípio da conservação das massas, pode-se determinar as vazões de diluição para diferentes concentrações permitidas, Tabela 2.

Tabela 2: Resultados da vazão de diluição para diferentes concentrações permitidas.

\begin{tabular}{c|c}
\hline Concentrações permitidas (mg/L) & Vazão de diluição $\left(\mathbf{m}^{3} \mathbf{s}\right)$ \\
\hline 20 & 7,36 \\
18 & 8,29 \\
16 & 9,46 \\
14 & 11,00 \\
14 & 13,00 \\
10 & 16,11 \\
8 & 20,85 \\
6 & 29,40 \\
5 & 36,80 \\
\hline
\end{tabular}

Fonte: Própria (2014).

A Figura 1 ilustra, graficamente, os resultados encontrados na Tabela 2. Os resultados representam a simulação de um lançamento de efluentes, com concentração de DBO de $300 \mathrm{mg} / \mathrm{L}$, lançada em um rio com concentração de DBO de $1 \mathrm{mg} / \mathrm{L}$. A vazão de lançamento do efluente é de $0,5 \mathrm{~m}^{3} / \mathrm{s}$. Neste caso, a simulação ocorreu para diferentes concentrações que definem as diversas classes dos rios. 
Figura 1: Vazão de diluição x Concentrações permitidas de DBO.

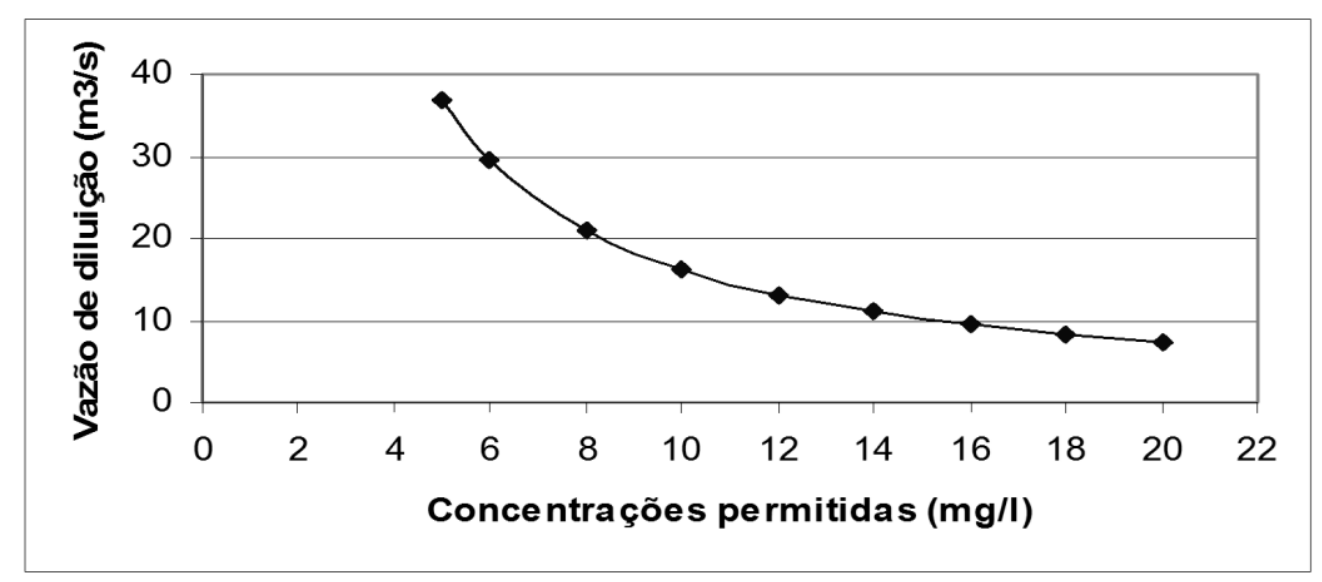

Fonte: Própria (2014).

$\mathrm{Na}$ Figura 1 estão os valores da vazão de diluição em função da concentração permitida. Pelos resultados se pode ver que, no lançamento de $300 \mathrm{mg} / \mathrm{L}$ de DBO, a vazão de diluição varia, aproximadamente, de $8 \mathrm{~m}^{3} / \mathrm{s}$ a $36 \mathrm{~m}^{3} / \mathrm{s}$, segundo a curva hiperbólica, com a concentração permitida variando de 20 a 5mg/L. Isto implica que, quanto menor for a classe do rio, maior serão os critérios de uso para concessão de outorgas. Esta conclusão pode ser verificada se for comparada a vazão de diluição de $20 \mathrm{~m}^{3} / \mathrm{s}$, para a concentração permitida de $8 \mathrm{mg} / \mathrm{L}$, com a vazão de diluição de $10 \mathrm{~m}^{3} / \mathrm{s}$, para a concentração permitida de $15 \mathrm{mg} / \mathrm{L}$.

Pela Tabela 3, observam-se as simulações para um rio de classe 1, cujo limite de DBO permitido é de $3 \mathrm{mg} / \mathrm{L}$. De acordo com os resultados, para esta classe de rio, a vazão de diluição requerida é maior que $50 \mathrm{~m} / \mathrm{s}$, o que impõe uma melhor análise para a concessão de outorga de lançamento. Verifica-se também que, para o lançamento de $200 \mathrm{mg} / \mathrm{L}$ de DBO, sem tratamento, a vazão requerida é de $50 \mathrm{~m}^{3} / \mathrm{s}$, valor significativo para os padrões dos rios do nordeste.

Tabela 3: Concentração de DBO (mg/L) x Vazão de diluição $\left(\mathrm{m}^{3} / \mathrm{s}\right)$ - rio Classe 1.

\begin{tabular}{c|c}
\hline Concentração de DBO (mg/L) & Vazão de diluição $\left(\mathbf{m}^{\mathbf{3}} / \mathbf{s}\right)$ \\
\hline 200 & 49,25 \\
300 & 74,25 \\
400 & 99,25 \\
500 & 124,25 \\
600 & 149,25 \\
700 & 174,25 \\
800 & 199,25 \\
\hline
\end{tabular}

Fonte: Própria (2014). 
As Figuras 2 e 3 ilustram, para um rio de classe 2, os resultados da vazão de diluição onde os limites para coliformes e DBO são, respectivamente, <1000 $\mathrm{NMP} / 100 \mathrm{~mL}$ e $<5 \mathrm{mg} / \mathrm{L}$. Neste caso, verifica-se que, para uma vazão de lançamento de $200 \mathrm{mg} / \mathrm{L}$ de DBO, a vazão de diluição requerida é $24,3 \mathrm{~m} 3 / \mathrm{s}$ enquanto que, para um lançamento de $800 \mathrm{mg} / \mathrm{l}$ de DBO, a vazão de diluição requerida é 99,3 m3/s. Pelos resultados verifica-se que, para lançamento de efluentes em rios com baixa vazão, caso dos rios da região nordeste, há a necessidade de eficientes tecnologias de tratamento desses efluentes. Somente nas condições em que o efluente passa por algum tipo de tratamento é que é possível se estabelecer um programa de outorga.

Figura 2: Vazão de diluição x DBO - rio classe 2.

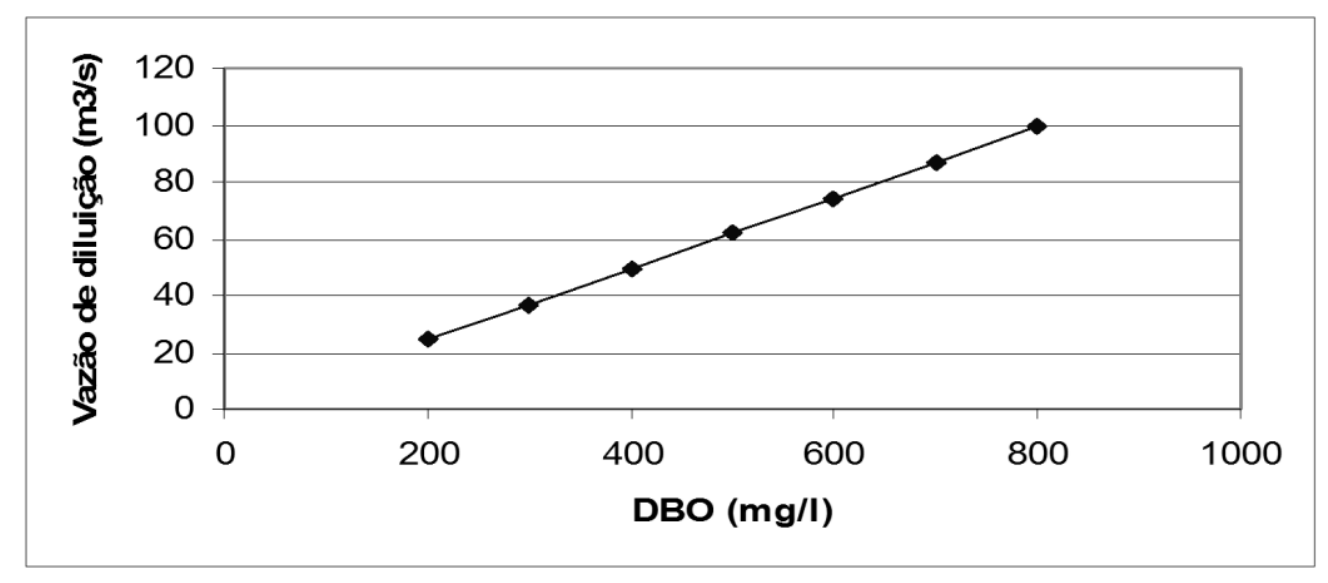

Fonte: Própria (2014).

Pela Figura 3 verifica-se que, em rios de classe 2 a vazão requerida para um lançamento de $5000 \mathrm{NMP} / 100 \mathrm{~mL}$ é $2 \mathrm{~m}^{3} / \mathrm{s}$ enquanto que, para um lançamento de $20000 \mathrm{NMP} / 100 \mathrm{~mL}$ a vazão é $9,51 \mathrm{~m}^{3} / \mathrm{s}$. De acordo com os resultados, em rios de classe 2 a vazão de diluição é compatível com principais rios da região nordeste em estações chuvosas. Isto implica que, as possibilidades de se estabelecer as outorgas, para estas condições, são reais. 
Figura 3: Vazão de diluição x Coliformes totais - rio classe 2.

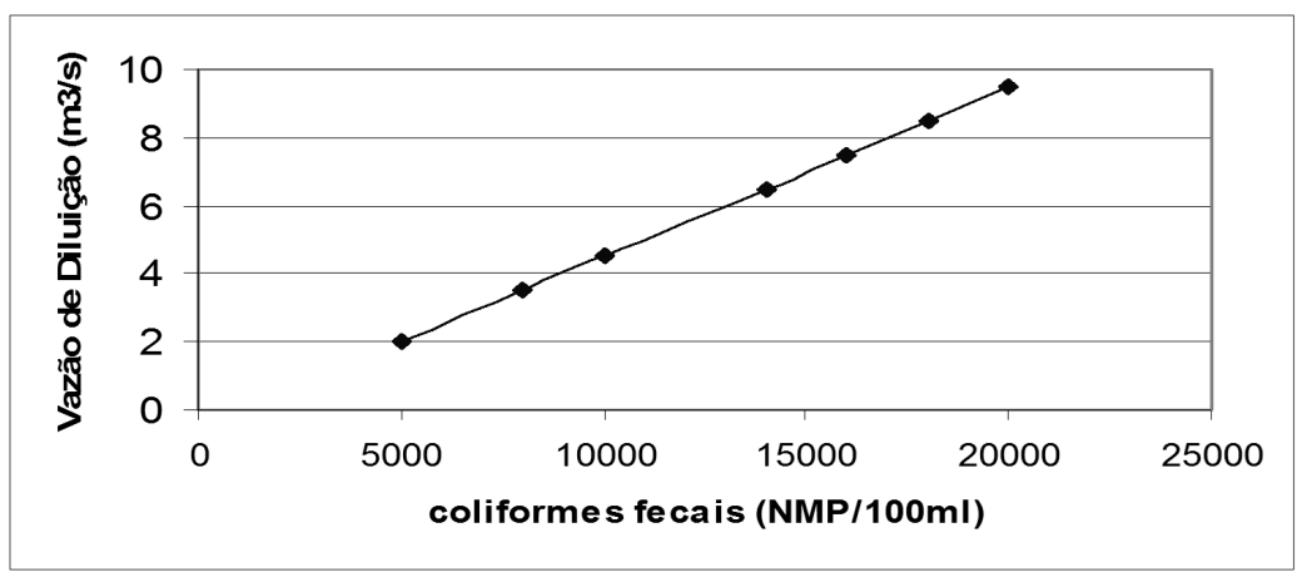

Fonte: Própria (2014).

As Figuras 4 e 5 ilustram os resultados da vazão de diluição para um rio de classe 3 , sendo os limites para coliformes e DBO de, respectivamente, $<4000$ $\mathrm{NMP} / 100 \mathrm{~mL}$ e $<10 \mathrm{mg} / \mathrm{L}$. Verifica-se com isto que, para uma vazão de lançamento de $200 \mathrm{mg} / \mathrm{L}$ de DBO a vazão de diluição requerida é $10,56 \mathrm{~m}^{3} / \mathrm{s}$ enquanto que, para um lançamento de $800 \mathrm{mg} / \mathrm{L}$ de DBO a vazão de diluição requerida é $43,89 \mathrm{~m} 3 / \mathrm{s}$.

Figura 4: Vazão de diluição x DBO - rio classe 3.

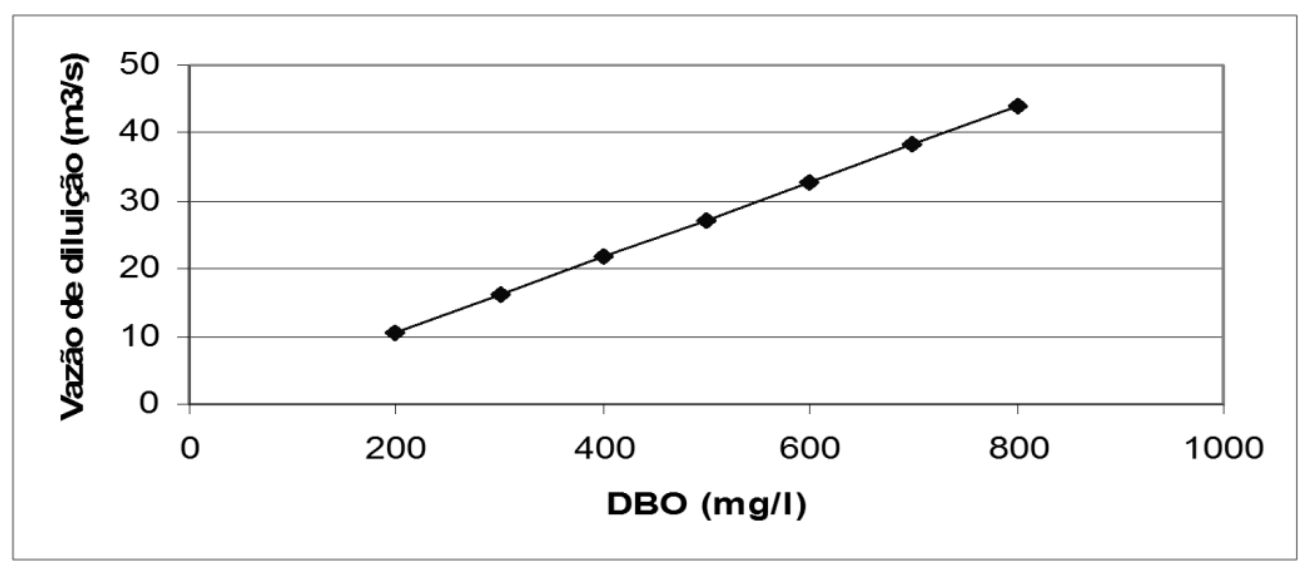

Fonte: Própria (2014).

Pelos resultados dos rios de classe 3 o sistema de outorga pode ser concedido com maior flexibilidade, uma vez que as vazões requeridas são compatíveis com as vazões disponíveis nos rios da Região Nordeste. A partir dos resultados apresentados na Figura 5 observa-se que, para rios de classe 3 , é 
possível se conceder um número maior de outorgas, já que a vazão de diluição requerida não é significativa.

Figura 5: Vazão de diluição x Coliformes totais - rio classe 3.

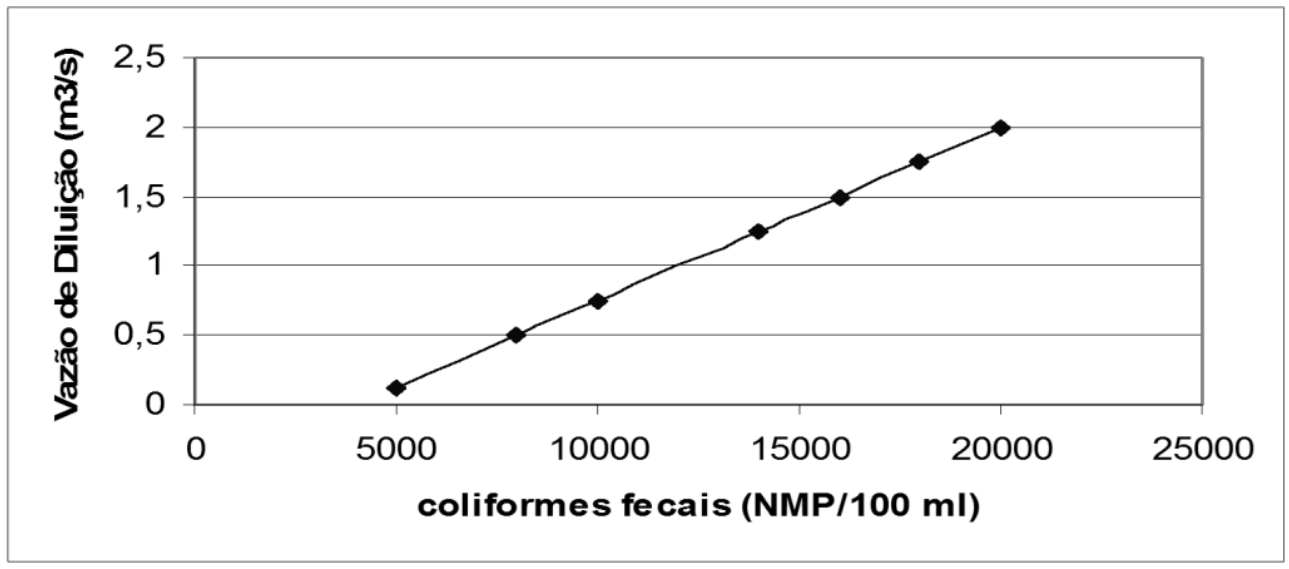

Fonte: Própria (2014).

Figura 6: Vazão de diluição x DBO - rio classe 3.

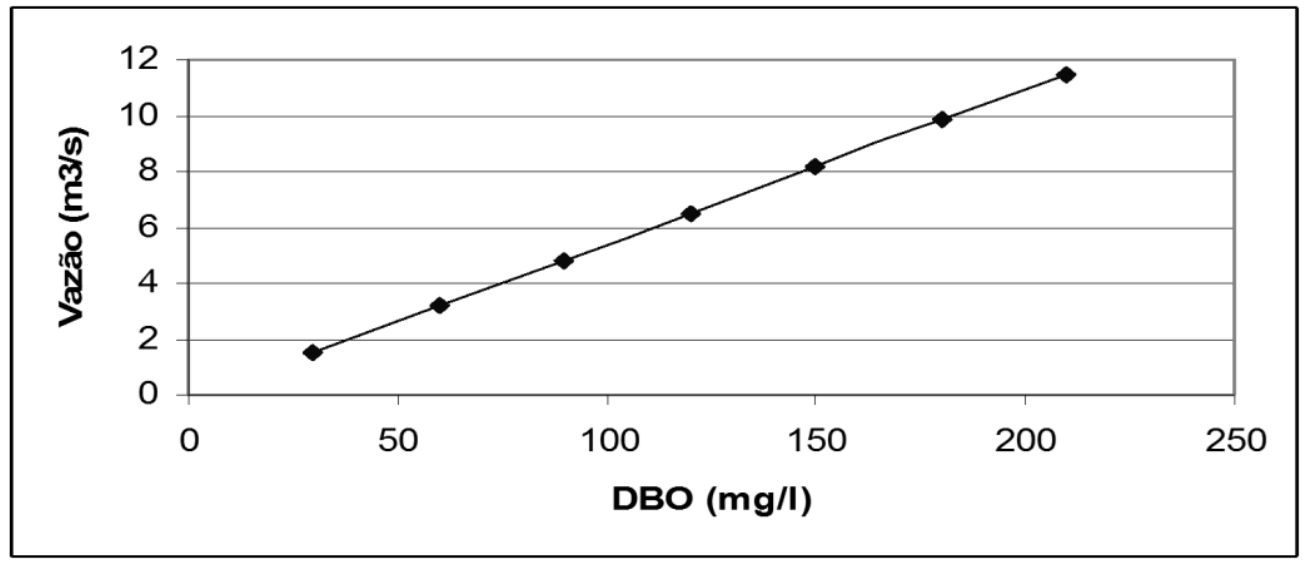

Fonte: Própria (2014).

A Figura 6 ilustra uma simulação em que se admite o processo de tratamento do efluente lançado em um rio de classe 3. Neste caso, as concentrações consideradas para DBO variaram de $30 \mathrm{mg} / \mathrm{L}$ a $210 \mathrm{mg} / \mathrm{L}$. Pelos resultados, as vazões de diluição requeridas caíram consideravelmente, passando de $1,5 \mathrm{~m}^{3} / \mathrm{s}$ para $11,5 \mathrm{~m}^{3} / \mathrm{s}$. No caso dos rios da região nordeste, estes resultados confirmam a necessidade de se fazer pré-tratamento dos efluentes lançados para que seja possível a concessão de outorga. 


\section{Periádica Eletranica

\subsection{APLICAÇÃO DA METODOLOGIA EM RIOS DO RIO GRANDE DO NORTE}

Depois de realizadas as simulações genéricas, ou seja, sem considerar um rio específico, aplicou-se o modelo em rios do Rio Grande do Norte. Como o estudo trata de concessão de outorga para o uso de lançamento de efluentes, foram realizadas algumas simulações em diferentes rios do Rio Grande do Norte, com bases nos dados disponíveis, de modo que fosse verificada qual a capacidade de autodepuração de cada um desses corpos d'água. Esses dados foram fornecidos pela SEMARH (Secretaria de Estado do Meio Ambiente e dos Recursos Hídricos). Os resultados serão apresentados e discutidos adiante. Todas as simulações foram feitas considerando rios de classe 2 .

A Tabela 4 apresenta os resultados das simulações realizadas para os rios Seridó, Taborda e Quiapuá, de acordo com suas respectivas vazões. Nestas simulações, foi admitido que as vazões dos efluentes não poderiam ultrapassar 0,01 $\mathrm{m} 3 / \mathrm{s}$, uma vez que têm valores baixos. De acordo com os resultados, somente o rio Seridó é capaz de receber efluentes sem tratamento primário. Os demais rios não suportariam qualquer tipo de lançamento sem tratamento adequado. Deve ficar claro que estas simulações foram realizadas para rios de classe 2, onde a máxima DBO permitida é $5 \mathrm{mg} / \mathrm{L}$ e o valor máximo de concentração de coliformes é 500 $\mathrm{NMP} / 100 \mathrm{~mL}$.

Tabela 4: Valores de coliformes e DBO permitidos para os rios de classe 2.

\begin{tabular}{c|c|c|c}
\hline Rios & Vazão $\left(\mathbf{m}^{3} / \mathbf{s}\right)$ & Coliformes $(\mathbf{N M P} / \mathbf{1 0 0 m L})$ & DBO (mg/L) \\
\hline Seridó & 0,230 & $114.977,0$ & 207,0 \\
Taborda & 0,085 & 42491,5 & 76,5 \\
Quiapuá & 0,087 & 43491,3 & 78,3 \\
\hline
\end{tabular}

Fonte: Própria (2014).

A Tabela 5 apresenta os resultados para os rios Trairi, Sabugi, Apodi e Pitinbú. Como pode ser verificado, levando em consideração que os rios utilizados nas simulações são de classe 2, somente os rios Pitimbú e Apodi não necessitam de sistemas de tratamento de efluentes. Os demais teriam seus cursos d'água comprometidos caso não houvesse sistema de tratamento adequado. Com isso, fica claro que a concessão de outorga para lançamentos passa por um critério de análise mais rigoroso. 
Tabela 5: Valores de Coliformes e de DBO permitidos para rios de Classe 2.

\begin{tabular}{c|c|c|c}
\hline Rios & Vazão $\left(\mathbf{m}^{\mathbf{3}} \mathbf{s}\right)$ & Coliformes $\mathbf{( N M P / 1 0 0 m L )}$ & DBO (mg/L) \\
\hline Trairi & 0,200 & $99.980,0$ & 180,0 \\
Sabugi & 0,218 & $108.978,0$ & 196,0 \\
Apodi & 0,717 & $358.428,0$ & 645,0 \\
Pitimbú & 1,200 & $599.880,0$ & $1.080,0$ \\
\hline
\end{tabular}

Fonte: Própria (2014).

A Tabela 6 apresenta os resultados das simulações para o rio Piranhas, em diferentes regiões por onde o mesmo passa. A Figura 7 ilustra, graficamente, estes resultados. De acordo com os dados, as características do rio variam bastante de trecho para trecho. A vazão, por exemplo, varia de $1 \mathrm{~m}^{3} / \mathrm{s}$ a $8 \mathrm{~m}^{3} / \mathrm{s}$. Deve ficar claro que rios com esta característica devem ser analisados trecho por trecho.

Tabela 6: Resultados do Rio Piranhas para Coliformes e DBO.

\begin{tabular}{c|c|c}
\hline Vazão $\left(\mathbf{m}^{\mathbf{3}} / \mathbf{s}\right)$ & Coliformes $(\mathbf{N M P} / \mathbf{1 0 0 m L})$ & DBO $(\mathbf{m g} / \mathbf{L})$ \\
\hline 1,000 & $49.990,0$ & 90,0 \\
2,500 & $124.975,0$ & 225,0 \\
4,700 & $234.953,0$ & 423,0 \\
8,390 & $419.416,1$ & 755,1 \\
\hline
\end{tabular}

Fonte: Própria (2014).

Figura 7: Concentrações permitidas de DBO para diferentes vazões do rio Piranhas.

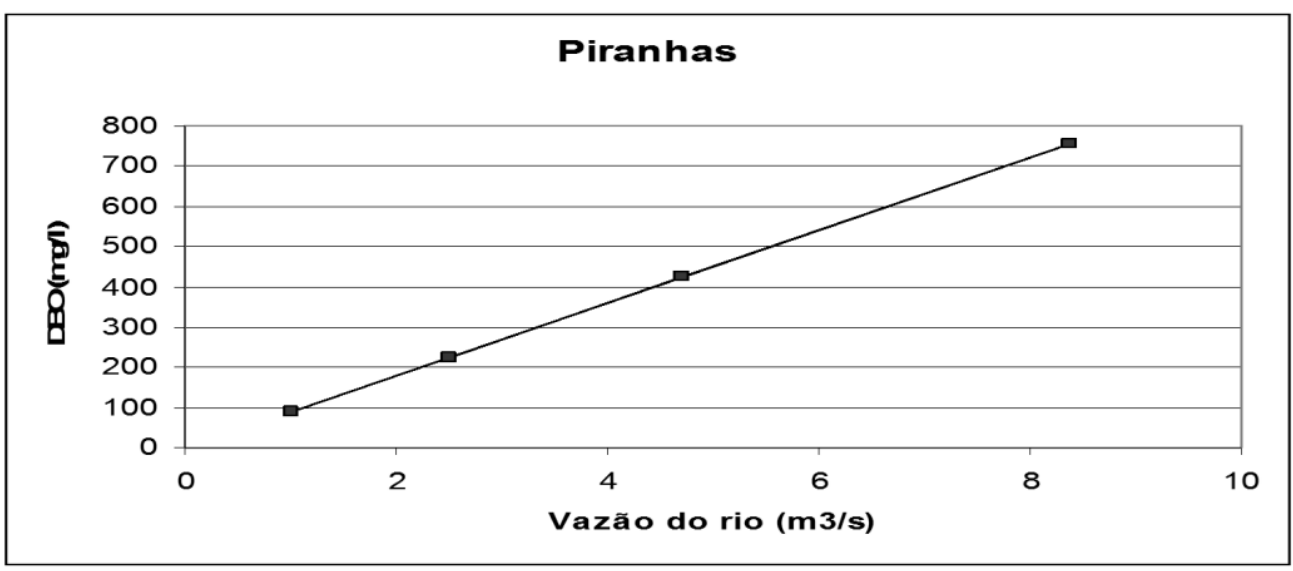

Fonte: Própria (2014).

De acordo com os resultados, para a vazão de $1 \mathrm{~m}^{3} / \mathrm{s}$ há a necessidade de se fazer o tratamento de efluentes, para qualquer tipo de efluente lançado. Isto 


\section{Periódica Eletranica

ocorre devido à vazão ser pequena e o sistema só comportar, no máximo, uma DBO de 90 mg/l, cujo valor, para esgotos domésticos, é bastante pequeno. Por outro lado, para a vazão de $8,39 \mathrm{~m}^{3} / \mathrm{s}$ a concentração de DBO que pode ser recebida por esse recurso hídrico, nesse trecho específico, é de 755,1 mg/L, valor mais significativo do que o citado anteriormente.

\section{CONCLUSÕES}

Verifica-se, ao final desta pesquisa, que a sistemática de outorga para lançamento de efluentes ainda é bastante embrionária a nível institucional. Vários fatores contribuem pata tal fato, dentre eles estão a falta de dados, para avaliar a capacidade de suporte dos sistemas hídricos, a falta de metodologia institucional que defina os processos de concessão de outorga, e a resistência dos usuários da água em solicitar a outorga de uso.

Entretanto, há um forte interesse a nível mundial, nacional e regional, no sentido de se estabelecer maior controle de uso da água através da concessão de outorga, em melhorar a qualidade dos corpos hídricos.

A partir dos resultados, vê-se a necessidade de se estudar, caso a caso, cada processo de concessão de outorga para o uso de lançamentos de efluentes. Pelos estudos, observa-se que uma metodologia adequada implica na necessidade de um banco de dados consistente das características dos rios que se pretende conceder a licença para este tipo de uso.

Ainda que, rios com variabilidade de vazões em diferentes trechos necessitam de análises para cada trecho, não permitindo, por sua vez, uma única análise de concessão de outorga. A prática de conceder a licença de uso com base em outros trechos pode trazer sérios ricos para a vida aquática no trecho em que foi concedida a outorga.

Por fim, há a necessidade de se fazer, caso possível, estudos em períodos de estiagem, uma vez que os rios estão vulneráveis a qualquer tipo de uso. A maioria dos rios do Rio Grande do Norte analisados neste estudo, por exemplo, não tem autonomia para receber cargas poluentes sem que haja significativos riscos de contaminação das águas. 


\section{REFERÊNCIAS BIBLIOGRÁFICAS}

CRUZ, J. C. Disponibilidade hídrica para outorga: avaliação de aspectos técnicos e conceituais. Tese (Doutorado em Engenharia de Recursos Hídricos e Saneamento Ambiental). Departamento de Hidráulica e Saneamento. Universidade Federal do Rio Grande do Sul. Porto Alegre, 2001. 189 p.

MACHADO, E.; PORTO, M.; RAMON, N.; FEIL, A. Um Avanço na Gestão da Qualidade de Água: A outorga de lançamento de efluentes. Anais.. XV Simpósio Brasileiro de Recursos Hídricos, 2003.

NAHON, I. M. Sistema de Apoio a Análise de Outorga de Lançamento de Efluentes para a Variável Demanda Bioquímica de Oxigênio: Estudo de caso da Bacia do Alto Iguaçu. Dissertação (apresentada como requisito parcial a obtenção do título de mestre em Engenharia de Recursos Hídricos e Ambiental), Universidade Federal do Paraná, 2006.

SILVA, L. M. e LANNA, A. E. Critérios de outorga de uso da água com base em modelagem agrohidrológica: metodologia e aplicação (bacia do rio Branco - BA). Anais.. XII Simpósio Brasileiro de Recursos Hídricos, 1997.

\section{AGRADECIMENTOS}

Os autores agradecem à Coordenadoria de Capacitação de Recursos Humanos Programa de Demanda Social (CAPES) e Conselho Nacional de Desenvolvimento Científico e Tecnológico (CNPq), pelo apoio à pesquisa. 